\title{
Evaluation of Process Uncertainty in Activated Sludge Treatment by Probabilistic Modeling
}

\author{
Ayanangshu Dey, M.ASCE ${ }^{1}$; and Benjamin S. Magbanua Jr. ${ }^{2}$
}

\begin{abstract}
Simulation-based design and analysis of biotreatment systems depends to a great extent on the accuracy of the model parameters used. In many cases, site-specific parameter estimates are not available and parameter values recommended in the literature are adopted along with a measure of judgment to account for bioprocess uncertainty. To better quantify process certitude associated with this approach and thus provide guidance to process designers lacking site-specific parameter values, stochastic simulations were conducted and the empirical frequency distributions derived from the simulation results were interpreted in terms of process certitude. In general, the simulation results confirmed field experience and current practice in biotreatment from a probabilistic standpoint and provided context in terms of process certitude. The certitude of achieving specific treatment levels increased with sludge age, validating the application of a design safety factor on the minimum solids retention time. The increase in process certitude was not substantial, however, beyond a sludge age of about 4 days for the removal of organic material or about 10 days for the removal of ammonia. Process certitude was also declined when the hydraulic behavior of the treatment system approached complete mixing, which could result from such operational strategies as increasing the recycle ratio or the utilization of step feed. DOI: 10.1061/(ASCE)EE.1943-7870.0000570. ( 2012 American Society of Civil Engineers.
\end{abstract}

CE Database subject headings: Biological processes; Activated sludge; Stochastic models; Uncertainty principles; Probability.

Author keywords: Biological treatment; Activated sludge; Stochastic modeling; Process uncertainty; Activated sludge model number 1.

\section{Introduction}

Biotreatment process design and analysis involves the application of mathematical relationships along with appropriate biokinetic parameter values to determine and evaluate design and operating parameters required to meet treatment objectives. The selection of biokinetic parameter values, however, inherently entails some uncertainty because the performance of a specific bioprocess installation cannot be fully known in advance. Furthermore, the scale of a project may not justify the acquisition of detailed kinetic and stoichiometric data or the use of a simulation-based approach. Safety factors are consequently utilized to account for uncertainties stemming from inadequate understanding or characterization of the biotreatment process. Their selection, however, is heuristically based, and common safety factors tend to provide a design that is very conservative with respect to achieving typical effluent goals. For example, a typical activated sludge system has an implied safety factor of 10-80 based on the minimum solids retention time necessary to sustain biomass growth (Rittmann and McCarty 2001).

The design and analysis of activated sludge systems has been greatly facilitated by computer-based simulation. Activated Sludge Model No. 1 (ASM1) was developed to simulate carbon and nitrogen removal systems (Henze et al. 1987a, b), and includes eight

\footnotetext{
${ }^{1}$ Senior Consultant, Water and Wastewater Engineering, JB Enviro Consultants Private Limited, Kolkata 700 075, India; formerly, Graduate Student, Civil and Environmental Engineering, Mississippi State Univ., Mississippi State, MS (corresponding author). E-mail: ayan1973@gmail.com

${ }^{2}$ Associate Professor, Dept. of Civil and Environmental Engineering, Mississippi State Univ., Mississippi State, MS.

Note. This manuscript was submitted on July 7, 2011; approved on March 15, 2012; published online on September 14, 2012. Discussion period open until March 1, 2013; separate discussions must be submitted for individual papers. This paper is part of the Journal of Environmental Engineering, Vol. 138, No. 10, October 1, 2012. (C) ASCE, ISSN $0733-$ 9372/2012/10-1040-1047/\$25.00.
}

processes, 13 components, five stoichiometric coefficients, and 14 kinetic parameters (Table 1). Substantial work has been done to validate ASM1 and to calibrate its parameters, and recommended parameter values and ranges provided by the model developers continue, for the most part, to be widely accepted or at any rate serve as a starting point for system simulation and design. Model calibration based on field performance of full-scale installations (e.g., Kappeler and Gujer 1992; Siegrist and Tschui 1992; Garman et al. 1996; and Petersen et al. 2002) has provided a range of parameter estimates whose distributions have, in turn, been characterized (Cox 2004). The incorporation of ASM1 and its successor models into a number of software packages designed specifically for wastewater bioprocess simulation and analysis has facilitated these developments and has also served to promote widespread acceptance and adoption of the model.

Performance evaluation of wastewater treatment plants by uncertainty analysis is a relatively new approach in decision making and assessing the uncertainty associated in achieving treatment objectives. Belia et al. (2008) concluded that the field of uncertainty analysis of wastewater models is in an initial stage as there are a range of topics that need more research. This particular aspect of bioprocess modeling has since been studied by several researchers in the recent past.

Refsgaard et al. (2007) proposed a general framework and guidance of role and interaction of uncertainty in environmental modeling process using an array of different methods. Others like Benedetti et al. (2006), Neumann et al. (2007), Martin et al. (2007), and Sin et al. (2008) have used the Monte Carlo simulation technique to address a variety of issues concerning water-related research. More recently, Flores-Alsina et al. (2008) used the same technique in evaluating wastewater treatment control strategies and addressed critical issues like variation in degree of fulfillment of control objectives, identification of environmental, legal, techni$\mathrm{cal}$, and economic contribution to existing variability, and the impact of control strategies during selection of alternatives. A more 
Table 1. Typical Parameter Values, Ranges, and Distribution at Neutral $\mathrm{pH}$ and $20^{\circ} \mathrm{C}$ for Domestic Wastewater (Dey and Magbanua 2010, Courtesy of Mary Ann Liebert, Inc.; Data from Cox 2004)

\begin{tabular}{|c|c|c|c|c|}
\hline \multirow[b]{2}{*}{ Symbol } & \multirow[b]{2}{*}{ Units } & \multicolumn{2}{|c|}{ Statistical parameters } & \multirow[b]{2}{*}{ Mean value } \\
\hline & & $\xi$ & $\sigma$ & \\
\hline \multicolumn{5}{|c|}{ Heterotrophic coefficients } \\
\hline$Y_{H}$ & mg biomass COD formed/mg COD oxidized & -0.45 & 0.12 & 0.64 \\
\hline$\mu_{H}$ & day $^{-1}$ & 1.14 & 0.60 & 3.13 \\
\hline$K_{S}$ & $\mathrm{mg} \mathrm{COD} / \mathrm{L}$ & 1.44 & 0.76 & 4.22 \\
\hline$b_{H}$ & day $^{-1}$ & -1.06 & 0.81 & 0.35 \\
\hline$K_{\mathrm{NO}}$ & $\mathrm{mg} \mathrm{NO}_{3}^{-}-\mathrm{N} / \mathrm{L}$ & -1.55 & 1.01 & 0.21 \\
\hline$K_{O, H}$ & $\mathrm{mg} \mathrm{O}_{2} / \mathrm{L}$ & -1.46 & 0.83 & 0.23 \\
\hline & Fraction & $\mathrm{a}$ & a & 0.50 \\
\hline \multicolumn{5}{|c|}{ Autotrophic coefficients } \\
\hline$Y_{A}$ & $\mathrm{mg}$ biomass COD formed/mg $\mathrm{N}$ oxidized & -1.52 & 0.55 & 0.22 \\
\hline$\mu_{A}$ & day $^{-1}$ & -0.51 & 0.44 & 0.60 \\
\hline$b_{A}$ & day $^{-1}$ & -1.97 & 0.28 & 0.14 \\
\hline$K_{\mathrm{NHNH}}$ & $\mathrm{mg} \mathrm{NH} \mathrm{N}_{3}-\mathrm{N} / \mathrm{L}$ & -0.68 & 1.00 & 0.51 \\
\hline$K_{0, A}$ & $\mathrm{mg} \mathrm{O}_{2} / \mathrm{L}$ & -0.82 & 0.96 & 0.44 \\
\hline \multicolumn{5}{|c|}{ Hydrolysis coefficients } \\
\hline$k_{h}$ & mg slowly biodegradable COD/mg cell COD-day & 0.83 & 0.36 & 2.29 \\
\hline$K_{X}$ & $\mathrm{mg}$ slowly biodegradable $\mathrm{COD} / \mathrm{mg}$ cell $\mathrm{COD}$ & -2.82 & 1.34 & 0.06 \\
\hline$\eta_{h}$ & Fraction & -0.86 & 0.62 & 0.42 \\
\hline \multicolumn{5}{|c|}{ Other coefficients } \\
\hline$f^{\prime}{ }_{D}$ & $\mathrm{mg}$ debris $\mathrm{COD} / \mathrm{mg}$ biomass $\mathrm{COD}$ & $\mathrm{b}$ & $\mathrm{b}$ & 0.08 \\
\hline$i_{\mathrm{N} / \mathrm{XB}}$ & $\mathrm{mg} \mathrm{N} / \mathrm{mg}$ COD in active biomass & $\mathrm{b}$ & $\mathrm{b}$ & 0.086 \\
\hline$i_{\mathrm{N} / X D}$ & $\mathrm{mg} \mathrm{N} / \mathrm{mg}$ COD in biomass debris & $\mathrm{b}$ & $\mathrm{b}$ & 0.06 \\
\hline$k_{a}$ & $\mathrm{~L} / \mathrm{mg}$ biomass $\mathrm{COD}-\mathrm{h}$ & $\mathrm{b}$ & $\mathrm{b}$ & 0.1608 \\
\hline
\end{tabular}

Note: $\mathrm{COD}=$ chemical oxygen demand.

${ }^{\mathrm{a}} \eta_{g}$ follows a uniform probability density function with a minimum of 0.10 and a maximum of 0.90 .

${ }^{\mathrm{b}}$ Values represent recommended parameter values.

specific approach of estimating uncertainty due to stoichiometry, biokinetics, influent fractions, hydraulics, mass transfer, and their combination was studied by Sin et al. (2009) using the Monte Carlo simulation process to address practical engineering questions. Further, Sin et al. (2011) showed that a global sensitivity analysis can be useful to prioritize possible sources of uncertainty and quantify their effect on performance in wastewater treatment plant design.

Further, Flores-Alsina et al. (2008) indicated that the Monte Carlo simulation technique is a practical method to mimic the intrinsic random behavior of biological processes using deterministic models. Benedetti et al. (2010) used triangular probability density functions (PDFs) of ASM1 parameters as suggested by Rousseau et al. (2001) and Reichert and Vanrolleghem (2001) for studying multicriteria analysis of wastewater treatment plant design and control scenario. In analyzing the uncertainty of the model application for a wastewater treatment plant, Sin et al. (2009) assumed uniform probability distribution for all biokinetic parameters with three classes of predefined uncertainty corresponding to 5, 25, and $50 \%$ of variability around their mean values, an approach earlier proposed by Brun et al. (2002). Deterministic multicriteria analysis was performed by Flores-Alsina et al. (2008) to include the variability in activated sludge model (ASM) parameters by using their probability distribution functions based on available knowledge.

This current study specifically explored the relationship between biokinetic uncertainty, process design, with three different flow regimes, e.g., completely mixed, plug flow, and stepfeed, and treatment performance of activated sludge (AS). Probabilistic modeling was conducted to develop data that could permit identification or at least inform the selection of design and operational strategies and of design safety factors that enhance the level of certitude in achieving wastewater treatment targets. In this context, it would be relevant to mention that "certitude" can be defined as the certainty or statistical probability of achieving any stipulated treatment target in an activated sludge process as stochastic simulation results are plotted to generate empirical cumulative frequency distributions (CFDs) for effluent concentrations under defined operating conditions.

\section{Methodology}

Probability density functions for the different model parameters obtained by Cox (2004) through Bayesian analysis of expertrecommended values and field calibration results were used for stochastic simulation. Of the 19 ASM1 parameters (Table 1), four $\left(f_{D}^{\prime}, i_{\mathrm{N} / \mathrm{XB}}, i_{\mathrm{N} / \mathrm{XD}}\right.$, and $\left.k_{a}\right)$ were considered invariant with respect to the specific treatment setting, while $14\left(Y_{H}, b_{H}, \hat{\mu}_{H}, K_{S}, K_{\mathrm{NO}}\right.$, $K_{O, H}, Y_{A}, \hat{\mu}_{A}, b_{A}, K_{\mathrm{NH}}, K_{O, A}, k_{h}, K_{X}$, and $\eta_{h}$ ) conformed with lognormal PDFs (Eq. 1) and one $\left(\eta_{g}\right)$ with a uniform PDF (Eq. 2)

$$
\begin{gathered}
P(x) \frac{1}{x \sigma \sqrt{2 \pi}} \exp \left[-\frac{(\ln x-\xi)^{2}}{2 \sigma^{2}}\right] \\
P(x)= \begin{cases}\frac{1}{b-a}, & a \leq x \leq b, \\
0, & x<a \text { or } x>b\end{cases}
\end{gathered}
$$

where $P(x)=$ probability that a model parameter has a value $x ; \xi$ and $\sigma=$ central value and variance, respectively, of the logtransformed parameter values; and $a$ and $b=$ minimum and maximum, respectively, of the parameter values. Excel (Microsoft Corporation, Redmond, WA) was used to generate 1,000 random combinations of parameter values according to their respective PDFs. Use of 1,000 random combinations was found reasonable to contain adequate sample space and thus be representative of the possible trend of PDF for any particular effluent parameter. 
Table 2. Model Components (Dey and Magbanua 2010, Courtesy of Mary Ann Liebert, Inc.)

\begin{tabular}{lcc}
\hline Component & ASM1 symbol Concentration \\
\hline Particulate inert organic material & $X_{I}$ & 30 \\
Slowly biodegradable substrate & $X_{s}$ & 165 \\
Active heterotrophic biomass & $X_{B, H}$ & 0 \\
Active autotrophic biomass & $X_{B, A}$ & 0 \\
Debris from biomass death and lysis & $X_{D}$ & 0 \\
Inert soluble organic material & $S_{I}$ & 0 \\
Readily biodegradable substrate & $S_{S}$ & 115 \\
Oxygen & $S_{O}$ & 0 \\
Nitrate nitrogen & $S_{\mathrm{NO}}$ & 0 \\
Ammonia nitrogen & $S_{\mathrm{NH}}$ & 25 \\
Soluble biodegradable organic nitrogen & $S_{\mathrm{ND}}$ & 6.5 \\
Particulate biodegradable organic nitrogen & $X_{\mathrm{ND}}$ & 8.5 \\
Alkalinity & $S_{\mathrm{ALK}}$ & 5.0 \\
\hline
\end{tabular}

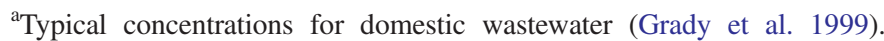
Concentrations are expressed in $\mathrm{mg} / \mathrm{L}$ chemical oxygen demand for organic components, $\mathrm{mg} / \mathrm{L} \mathrm{N}$ for nitrogenous species, and $\mathrm{mM} / \mathrm{L}$ for alkalinity.

Activated sludge process simulations were performed using GPS-X (Hydromantis, Inc., Hamilton, Ontario, Canada). All simulations were performed using influent properties typical of domestic wastewater (Table 2). Simulations were performed for three different AS process configurations [completely mixed activated sludge (CMAS), conventional activated sludge (CAS), and stepfeed activated sludge (SFAS)] at selected operating parameter ranges (Table 3) for each of the 1,000 parameter combinations obtained as described above. Hence, the stochastic simulations under the selected operating conditions each consisted of 1,000 Monte Carlo shots. In addition, discrete simulations were performed using the mean parameter values (Table 1). Steady state effluent concentrations were obtained by relaxation, i.e., allowing simulations to run for at least five times the adopted solids retention time (SRT), until the state variables converged. In all simulations, the secondary clarifier was modeled as an ideal biomass separator achieving $100 \%$ particulate removal efficiency to eliminate the influence of physical separation and focus on the effect of the biochemical processes on overall system performance. Consequently, the effluent contained only soluble components, i.e., $S_{S}$ and $S_{I}(=0)$ for organic species and $S_{\mathrm{NH}}, S_{\mathrm{NO}}$, and $S_{\mathrm{ND}}$ for nitrogenous species. The dissolved oxygen (DO) set point in the aeration tank was $2.0 \mathrm{mg} / \mathrm{L}$ to ensure that biokinetics were not oxygen limited. Wastage was withdrawn directly from the aeration tank in accordance with the Garrett configuration (Grady et al. 1999) at the rate necessary to maintain the specified SRT. Stochastic simulation results were conducted to develop empirical CFDs for the effluent concentrations and examined using a number of graphical approaches to evaluate the certitude of attaining treatment targets under specific process conditions.

\section{Results and Discussion}

\section{Solids Residence Time}

The solids residence time (SRT) or sludge age is the principal design variable controlling biotreatment process performance. The sludge age is selected to ensure that the minimum SRT required to establish a stable microbial population, $\theta_{C}^{\mathrm{min}}$, is exceeded, usually by a significant factor of safety (Rittmann and McCarty 2001)

$$
\varsigma=\frac{\theta_{C}}{\theta_{C}^{\min }}=\theta_{C} \cdot(\hat{\mu}-b)
$$

where $\varsigma=$ safety factor; $\theta_{C}=$ SRT. and the model parameters $\hat{\mu}$ and $b$ are as defined in Table 1. Although the influent concentration is normally considered when calculating $\theta_{C}^{\min }$ and $\varsigma$, a concentrationindependent form, i.e., the limiting value at an infinitely high influent concentration, was used here in order to focus on the biokinetic parameters. For the mean parameter values and influent properties used in this study, $\theta_{C}^{\min }$ was about $0.4-d$ for heterotrophic growth and $2.2-d$ for autotrophic growth, with no significantly increase even if influent concentrations were considered. Autotrophs have a much higher $\theta_{C}^{\min }$ due to their slow growth relative to heterotrophs. Design safety factors are typically fairly high, and biotreatment systems are considered to operate at a high loading rate when $3 \leq \varsigma \leq 10$, at conventional loading when $10 \leq \varsigma \leq 80$, and at low loading when $\varsigma \geq 80$. Hence, when no site-specific parameters have been determined, $\varsigma$ provides some assurance to the design engineer that the desired microbial populations will be maintained within the treatment system. That certitude level could be assessed, however, by evaluating $\theta_{C}^{\text {min }}$ for each of the 1,000 parameter combinations and examining the empirical CFDs (Fig. 1).

The probability levels could be interpreted as the certitude that the associated SRT would equal or exceed the $\theta_{C}^{\mathrm{min}}$ in the biotreatment system. The $\theta_{C}^{\min }$ values calculated using the mean parameters corresponded to certitude levels that, not surprisingly, were near the midpoint of each CFD at around 54\% for heterotrophs $(0.4-d)$ and $52 \%$ for autotrophs $(2.2-d)$. Application of a safety factor of 10 to the $\theta_{C}^{\min }$ of each population, resulting in SRTs of $4-d$ for heterotrophs and $22-d$ for autotrophs, increased the certitude to $>99 \%$. Further gains in certitude, however, would come at the expense of greatly increasing the SRT and the safety factor.

Stochastic simulations of a CMAS system $(\theta=6-h ; R=0.5$; and $1 \leq \theta_{C} \leq 30-d$ ) were performed to further investigate the effects of SRT on system performance. For the model structure

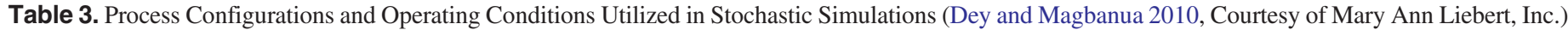

\begin{tabular}{|c|c|c|}
\hline Configuration & Description & Parameter range $\mathrm{e}^{\mathrm{a}}$ \\
\hline CMAS: Completely-mixed activated sludge & Completely-mixed aeration basin & $\theta_{c}: 1-30$ days; $\theta: 2-12 \mathrm{~h}$ \\
\hline CAS: Conventional activated sludge & $\begin{array}{l}\text { Plug flow aeration basin modeled as a series } \\
\text { of five completely-mixed tanks }\end{array}$ & $\theta_{c}: 1-30$ days; $R: 0.25-3.0$ \\
\hline SFAS: Step-feed activated sludge & $\begin{array}{l}\text { Plug flow aeration basin with influent distributed along } \\
\text { its length modeled as a series of five completely-mixed tanks } \\
\text { with provision to inject influent into each tank }\end{array}$ & $\begin{array}{l}\theta_{c}: 1-30 \text { days; } \\
\text { influent distribution: } 1 / 5-5 / 5 \text { tanks }\end{array}$ \\
\hline
\end{tabular}

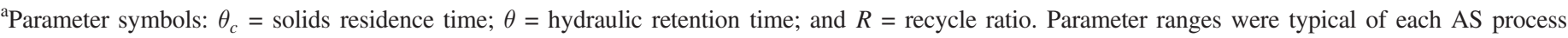

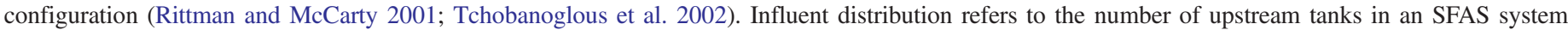

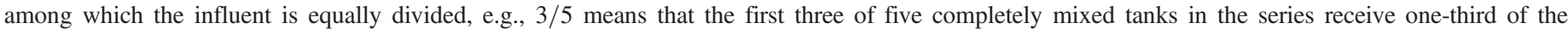
influent flow. 


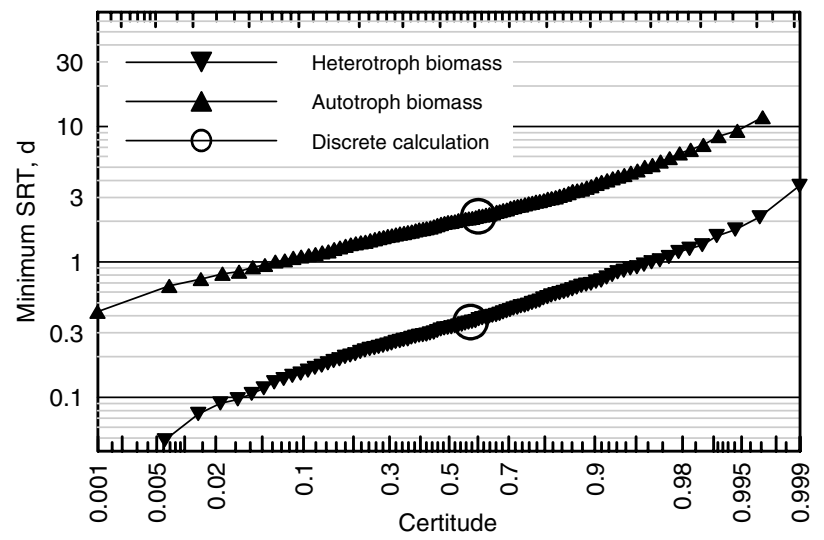

Fig. 1. Stochastic and discrete calculation of minimum SRT for heterotrophic and autotrophic biomass

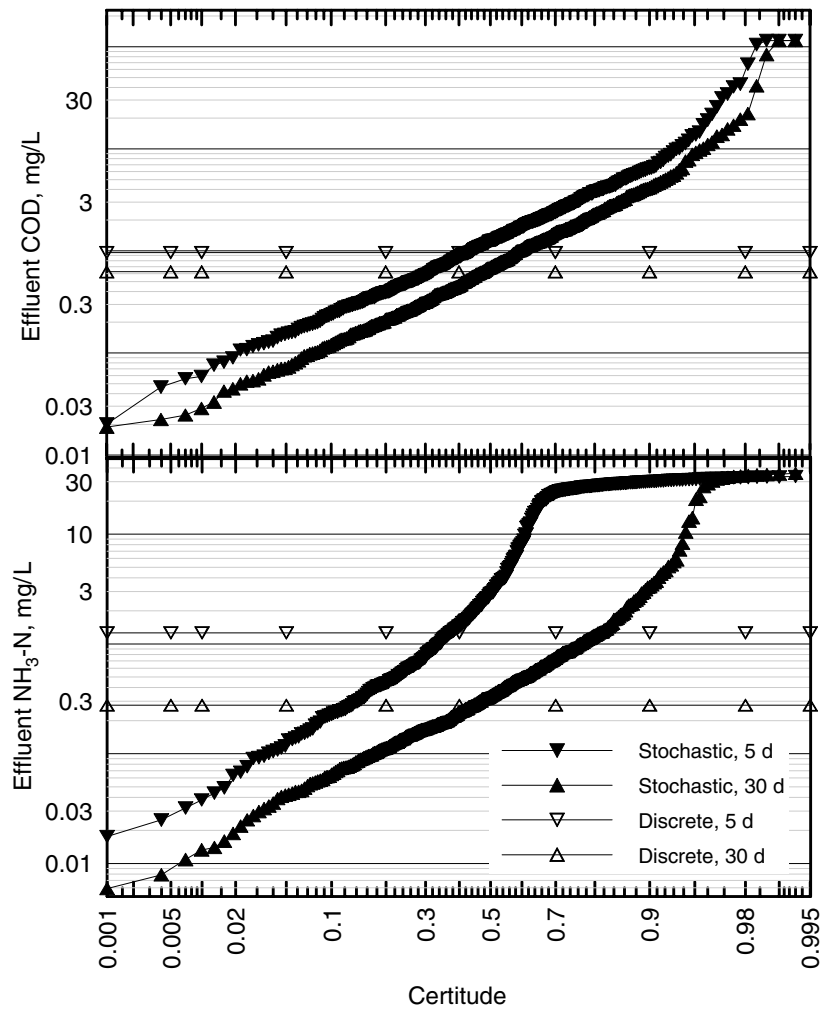

Fig. 2. Stochastic and discrete simulation of steady state effluent COD and $\mathrm{NH}_{3}-\mathrm{N}$ concentrations in a CMAS system

of ASM1, a CMAS system provides a conservative assessment of biotreatment performance at a particular SRT. The empirical CFDs of the steady state effluent concentrations (Fig. 2) could be interpreted in terms of the certitude that a certain effluent quality would be produced by the specified process configuration and operating conditions.

At a 5-day SRT, the discrete simulation predicted an effluent chemical oxygen demand (COD) concentration of $0.96 \mathrm{mg} / \mathrm{L}$. The corresponding CFD, however, suggested that the certitude of attaining this effluent COD concentration was about $43 \%$. That is, a CMAS system operated at 5-day SRT, 6-h HRT, and 0.5 recycle, treating a typical municipal wastewater described in Table 2, and designed using only the mean parameter values listed in Table 1 and no site-specific parameter estimates would have a
$43 \%$ certitude of achieving a COD effluent concentration of $0.96 \mathrm{mg} / \mathrm{L}$ or lower. Similarly, the discrete simulation predicted an effluent $\mathrm{NH}_{3}-\mathrm{N}$ concentration of about $1.26 \mathrm{mg} / \mathrm{L}$, corresponding to a certitude of about $37 \%$. Increasing the SRT to 30 days reduced the effluent $\mathrm{COD}$ and $\mathrm{NH}_{3}-\mathrm{N}$ to $0.63 \mathrm{mg} / \mathrm{L}$ (47\% certitude) and $0.28 \mathrm{mg} / \mathrm{L}$ ( $45 \%$ certitude), respectively. Since mean parameter values were used for the discrete simulations, it was not surprising that the associated certitude levels were close to $50 \%$. Interestingly, increasing the SRT resulted in a corresponding increase in certitude level even though the parameter PDFs and the specific parameter values used in the stochastic simulations were unchanged. Comparison of the CFDs at 5 and 30 days, corresponding to safety factors (12.5 and 75) within the conventional loading range for heterotrophs and in the high (2.7) to conventional (13.6) range for autotrophs, also showed the differing response of $\mathrm{COD}$ and $\mathrm{NH}_{3}-\mathrm{N}$ in a CMAS system. For COD, the CFD at 5 and 30 days were almost identical in shape, although the certitude levels were slightly higher at 30 days. The certitude that $\theta_{C}^{\min }$ for heterotrophs would be exceeded at an SRT of 5 days was already $99 \%$ (Fig. 1) so increasing SRT further did not greatly enhance the certitude of COD removal. For $\mathrm{NH}_{3}-\mathrm{N}$, similarly increasing the SRT resulted in a marked increase in certitude levels, which also decreased less rapidly, i.e., exhibited a flatter slope, as effluent $\mathrm{NH}_{3}-\mathrm{N}$ target levels became more stringent (Fig. 3).

The certitude that $\theta_{C}^{\min }$ for autotrophs would be exceeded was 89 and $99 \%$ at SRTs of 5 and 30 days, respectively. Hence, the certitude levels for attaining some target effluent concentration at a given SRT and for establishing a stable microbial population within the bioreactor were closely related.

The certitude of attaining a specific treatment goal as a function of the SRT (Fig. 3) was also plotted to further examine the effects of sludge age. As might be expected, greater certitude could be attained by selecting a less stringent treatment goal or a longer

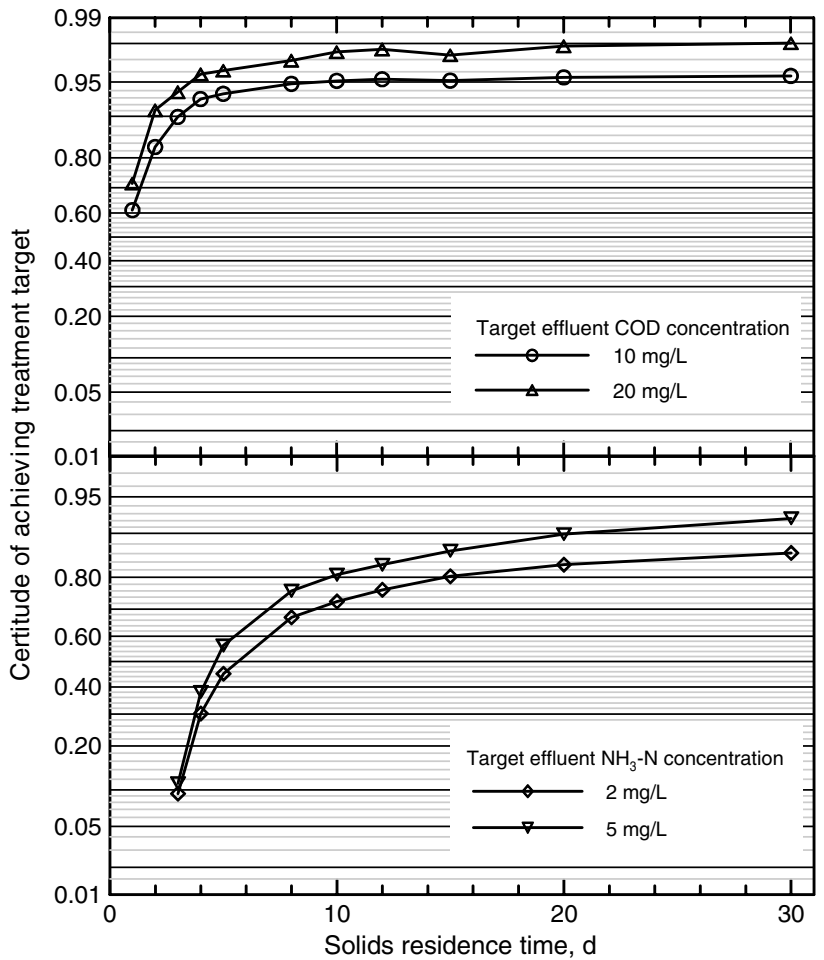

Fig. 3. Effect of SRT on certitude of obtaining specific target COD and $\mathrm{NH}_{3}-\mathrm{N}$ effluent concentrations in a CMAS system 
SRT. Two levels of treatment targets were selected for this analysis and these were 10 and $20 \mathrm{mg} / \mathrm{L}$ for effluent COD concentration and 2 and $5 \mathrm{mg} / \mathrm{L}$ for effluent $\mathrm{NH}_{3}-\mathrm{N}$. The benefits realized from increasing the SRT, however, differed for COD and $\mathrm{NH}_{3}-\mathrm{N}$. For COD removal, the certitude level at 5 days had attained around $95 \%$ and did not increase greatly as the SRT was increased. The certitude of $\mathrm{NH}_{3}-\mathrm{N}$ removal, on the other hand, benefitted more substantially, rising from around $40 \%$ at 5 days to about $90 \%$ at 30 days. Again, this difference was attributed to the much slower growth of autotrophs as compared to heterotrophs. In effect, the certitude that a stable nitrifying population could be maintained determines the certitude level of nitrogen removal.

Field experience in wastewater biotreatment indicates that an SRT of 0.5-2 days is required for removal of biogenic soluble organic matter, 2-4 days for removal of particulate organic matter, and 2-15 days for nitrification (Grady et al. 1999; Tchobanoglous et al. 2002). Hence, the stochastic simulation results were consistent with field experience and support the use of a multiplier on the minimum SRT as a safety factor.

\section{Reactor Configuration}

Stochastic simulations were likewise run for CAS and SFAS systems $\left(\theta=6-h ; R=0.5\right.$; and $\left.1 \leq \theta_{C} \leq 30-d\right)$ to compare their performance to a CMAS system. For the CAS system (Fig. 4), the CFDs for the effluent COD concentration at 5-and 30 day SRTs were almost identical so that the certitude of COD removal was essentially unaffected by the SRT. However, the certitude of $\mathrm{NH}_{3}-\mathrm{N}$ removal increased substantial as SRT increased from 5 to 30 days. Furthermore, comparison of Figs. 2 and 4 suggested that the CAS system could attain greater certitude of COD and $\mathrm{NH}_{3}-\mathrm{N}$ removal than a CMAS system operated at the same SRT. Superior biotreatment performance was expected in the

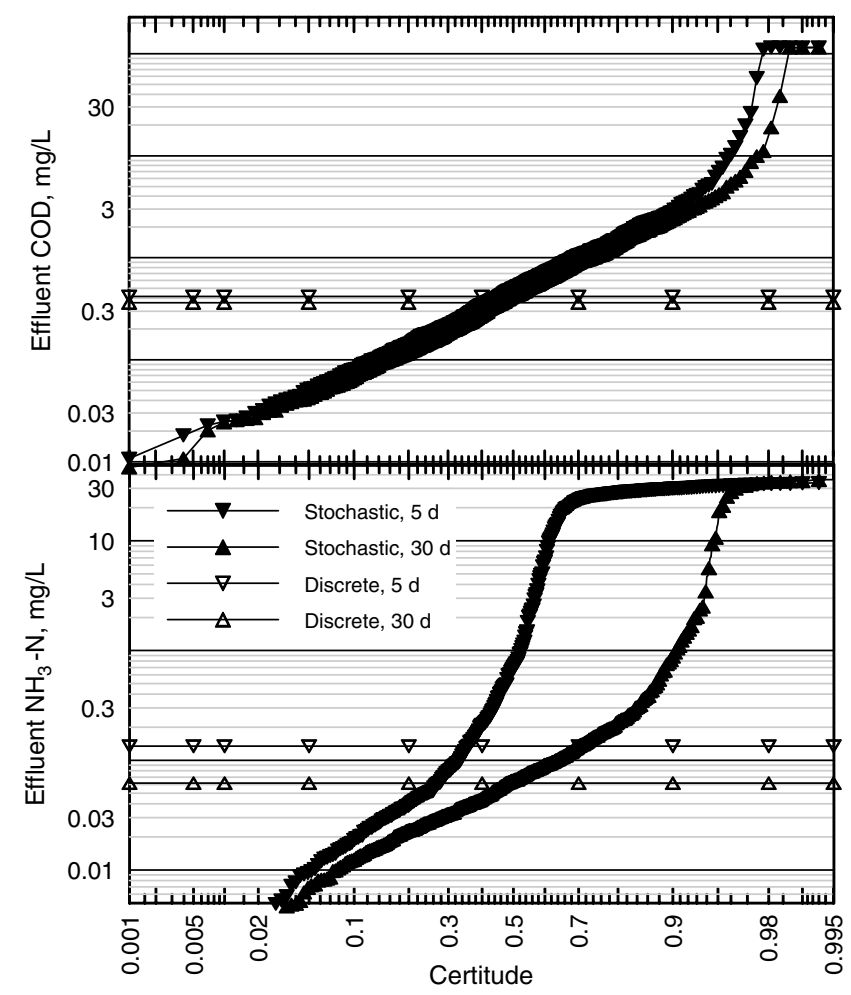

Fig. 4. Stochastic and discrete simulation of steady state effluent COD and $\mathrm{NH}_{3}-\mathrm{N}$ concentrations in a CAS system

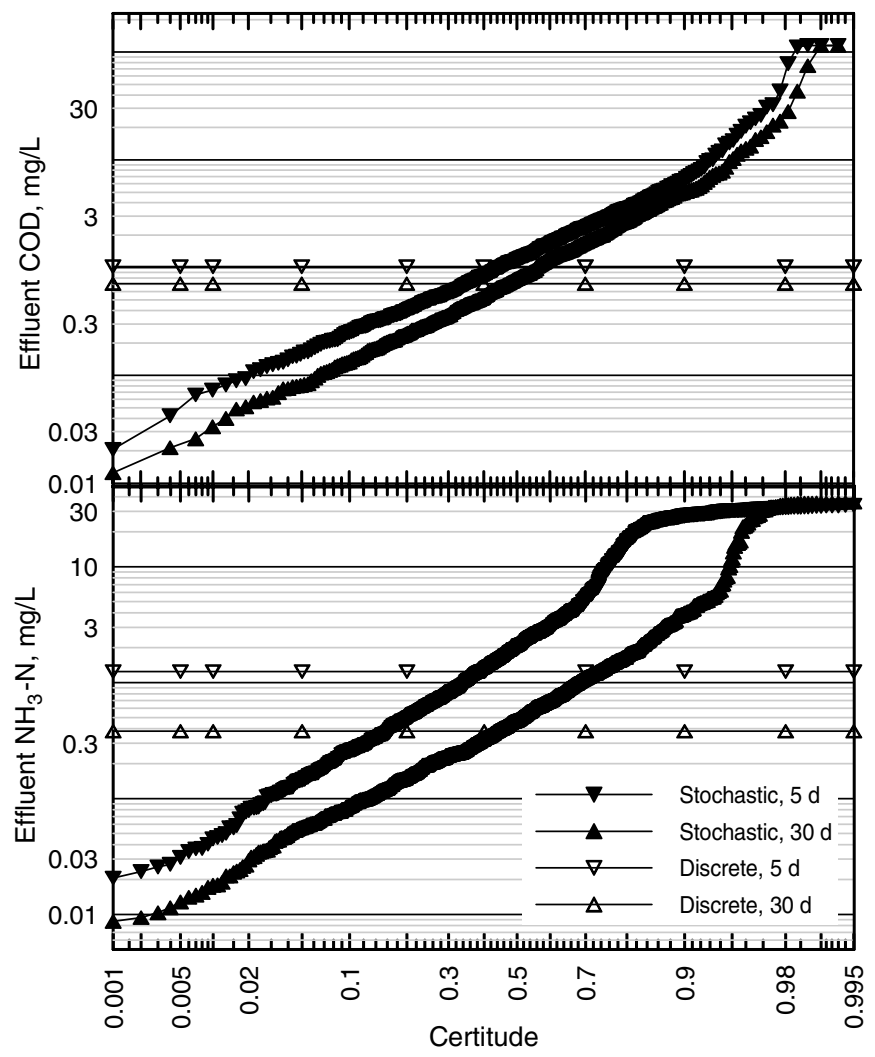

Fig. 5. Stochastic and discrete simulation of steady state effluent COD and $\mathrm{NH}_{3}-\mathrm{N}$ concentrations in an SFAS system

CAS system, as pointed out above, because the plug flow regime results in a concentration gradient that permits a higher average volumetric reaction rate within the aeration basin.

The certitude levels for attaining a specific treatment goal as a function of SRT were similar for CMAS (Fig. 3) and CAS (Fig. 6) systems, although the CMAS system appeared to experience a greater decrease in certitude when the treatment goal became more stringent.

For the SFAS system, the shape of the effluent concentration CFDs depended greatly on the influent distribution scheme. The mixing regime of the aeration basin approached plug flow when influent was injected solely into the first tank, and approached complete mixing when influent was distributed between all five tanks (Fig. 5). Consequently, SFAS behavior at these extremes was similar to the CAS or to the CMAS system, respectively.

\section{Hydraulic Retention Time}

Stochastic simulations of the CMAS system $\left(\theta_{C}=5-d ; R=0.5\right.$; and $2-h \leq \theta \leq 12-h$ ) indicated that the effect of HRT on the certitude of meeting COD treatment targets was minimal, particularly at an HRT beyond 4h (Fig. 7). For $\mathrm{NH}_{3}-\mathrm{N}$ removal, on the other hand, the certitude level was very low at $2 \mathrm{~h}$ and increased substantially with HRT.

\section{Recycle Ratio}

Stochastic simulations of a CAS system $\left(\theta_{C}=5-d ; \theta=6-h\right.$; and $0.25 \leq R \leq 3.0$ ) indicated that treatment certitude decreased very slightly with increasing recycle ratio. The hydraulic and kinetic behavior of the plug flow system with recycle approaches 


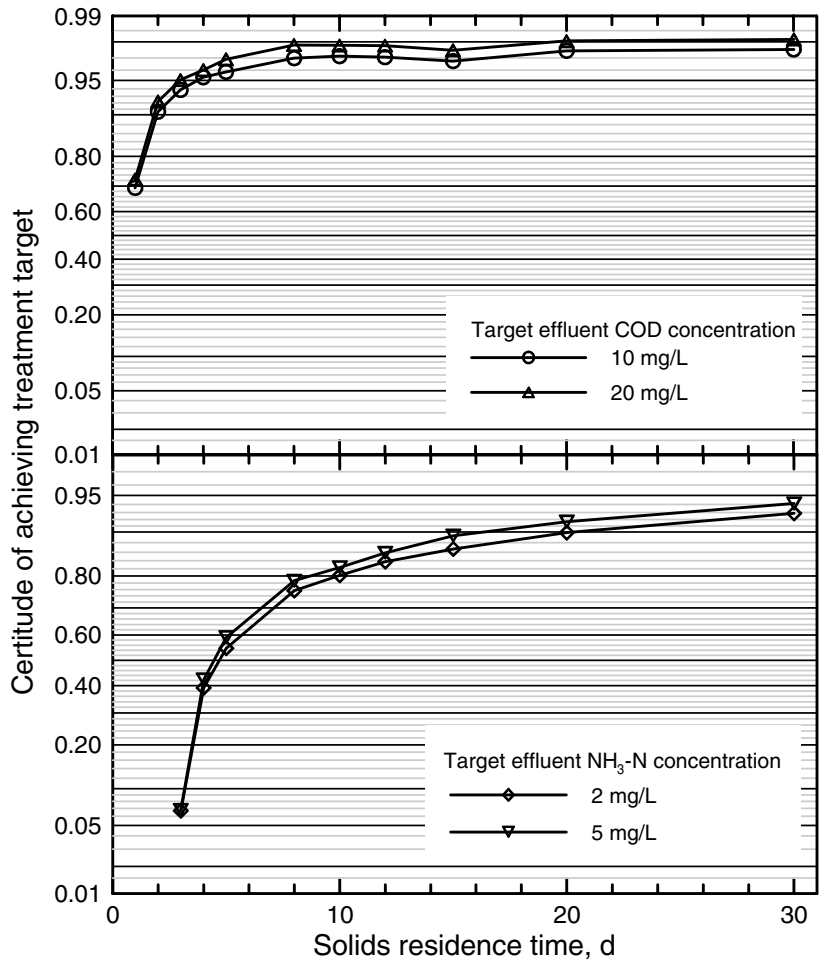

Fig. 6. Effect of SRT on certitude of obtaining specific target COD and $\mathrm{NH}_{3}-\mathrm{N}$ effluent concentrations in a CAS system

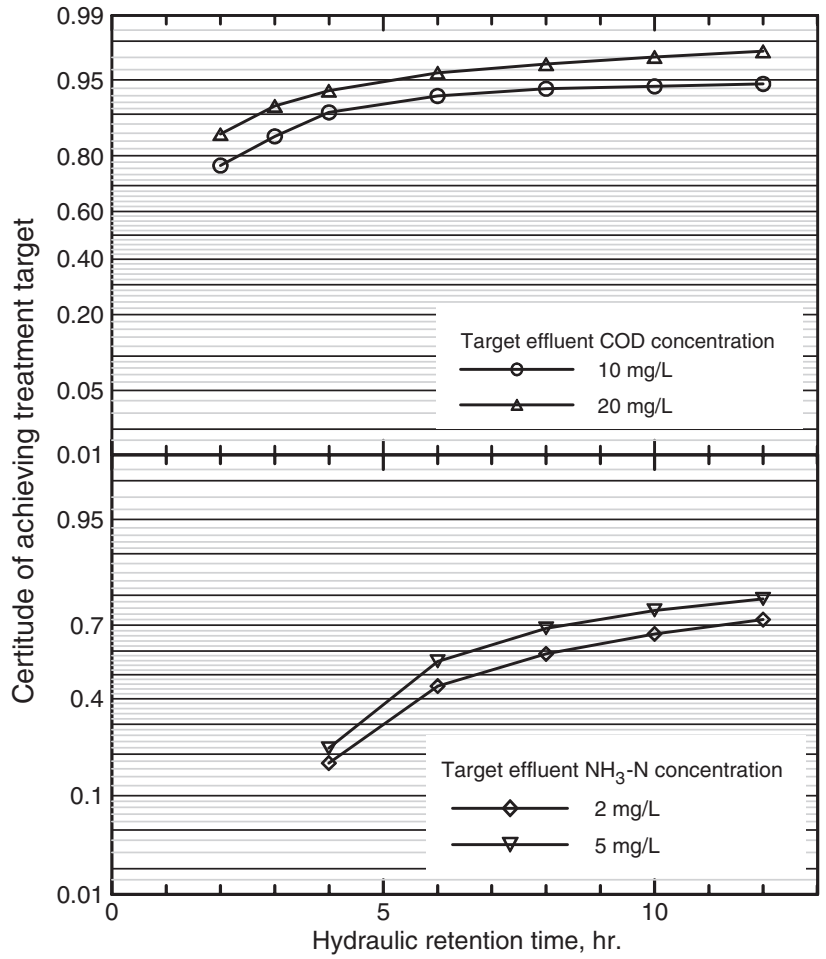

Fig. 7. Effect of HRT on certainty of achieving $\mathrm{COD}$ and $\mathrm{NH}_{3}-\mathrm{N}$ removal targets in a CMAS system

the completely mixed regime as the recycle ratio is increased (Gillespie and Carberry 1966; Magbanua Jr. and Bowers 1998). A CMAS system would not be similarly affected by the recycle ratio as complete mixing already prevails.

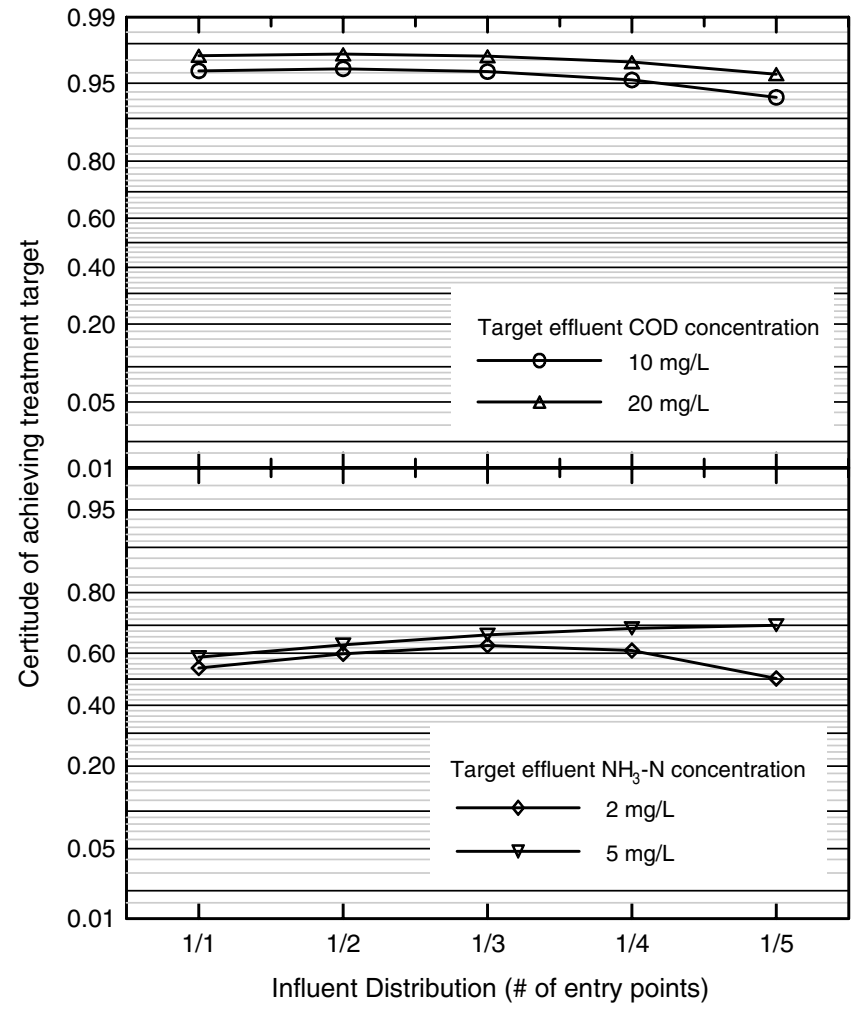

Fig. 8. Effect of influent distribution on certainty of achieving COD and $\mathrm{NH}_{3}-\mathrm{N}$ removal targets in an SFAS system

\section{Influent Distribution}

Stochastic simulations of an SFAS system $\left(\theta_{C}=5-d ; \theta=6-h\right.$; and $R=0.5)$ over a range of influent distribution scenarios $(1 / 5$ to $5 / 5)$ indicated that the certitude of meeting COD targets increased as the influent was distributed among fewer tanks (Fig. 8). Distributing the influent over a greater number of tanks reduced the maximum substrate concentration and flattened out the concentration gradient so that volumetric reaction rates were reduced and a treatment performance and certitude were degraded. However, the opposite trend was observed for $\mathrm{NH}_{3}-\mathrm{N}$ removal to $5 \mathrm{mg} / \mathrm{L}$, where the certitude decreased when influent was distributed among fewer tanks.

Distribution of the influent and the oxygen demand over a greater number of tanks may have permitted the autotrophs to more effectively compete for oxygen throughout the reactor, resulting in enhanced nitrification. However, $\mathrm{NH}_{3}-\mathrm{N}$ removal to $2 \mathrm{mg} / \mathrm{L}$ exhibited maximum certitude at an influent distribution of $3 / 5$. It is possible that the contact time between the wastewater and the autotrophs at influent distributions of $4 / 5$ and 5/5 was insufficient to ensure reliable attainment of the more stringent treatment target.

\section{Summary and Conclusion}

Stochastic simulation permitted quantitative evaluation of the certitude levels associated with activated sludge biotreatment. The relationship between variability of biokinetic parameters and predicted process performance was studied in this research effort.

Probability density functions for different stoichiometric and kinetic parameters as obtained by Cox (2004) through Bayesian analysis of expert-recommended values and field calibration results 
were used for stochastic simulation. Inclusion of such scientifically established range of variability of these parameters might be a logical approach for an uncertainty analysis of activated sludge systems. At each set of process conditions examined, 1,000 Monte Carlo simulations that used a unique set of parameter combinations were performed. The empirical cumulative distribution function of the simulation results suggested that this number was adequate for convergence to be attained.

Simulation results generally confirmed industry design practices that are based on both mechanistic and heuristic considerations, but provided an added perspective in terms of process certitude. In other words, while a typical design approach based on deterministic parameter values provides a deterministic prediction of process performance, a stochastic approach provided a level of certitude corresponding to specific treatment targets. The design process, then, changes from one where a design parameter is specified in order to meet some treatment standard to one where a tolerable level of certitude for achieving treatment requirements is selected and the design parameters are specified accordingly.

The observed effects of specific design and operating parameters on process certitude were

- Treatment certitude increased with SRT. This validates the use of a safety factor that serves as a multiplier for the minimum SRT. However, certitude of COD removal did not improve significantly when SRT exceeded 4 days nor did certitude for $\mathrm{NH}_{3}-\mathrm{N}$ removal when SRT exceeded 10 days.

- Treatment performance and certitude in a CAS system was generally superior to a CMAS system due to the mixing regime in the reactor.

- Treatment certitude increased with HRT, but improvement was slight beyond about $6 \mathrm{~h}$ for COD removal or $10 \mathrm{~h}$ for $\mathrm{NH}_{3}-\mathrm{N}$ removal.

- Operational strategies that shifted the mixing regime away from plug flow reduced the performance and certitude of the biotreatment process. Such changes included increasing the recycle ratio in a CAS system, although this effect was minimal, and distributing the influent along a greater length of the aeration basin in an SFAS system.

\section{Acknowledgments}

This material is based upon work supported in part by the National Science Foundation under Grant No. BES-0348161 and by the Mississippi Department of Environmental Quality under Work Order No. 05-0001MSU-006.

\section{Notation}

The following symbols are used in this paper:

$b_{A}=$ decay coefficient for autotrophic biomass;

$b_{H}=$ decay coefficient for heterotrophic biomass;

$f^{\prime} D=$ fraction of biomass leading to debris;

$i_{\mathrm{N} / \mathrm{XB}}=$ mass of nitrogen per mass of COD in biomass;

$i_{\mathrm{N} / \mathrm{XD}}=$ mass of nitrogen per mass of COD in products from biomass;

$K_{\mathrm{NH}}=$ ammonia half-saturation coefficient for autotrophic biomass;

$K_{\mathrm{NO}}=$ nitrate half-saturation coefficient for denitrifying heterotrophic biomass;

$K_{O, A}=$ oxygen half-saturation coefficient for autotrophic biomass;

$K_{O, H}=$ oxygen half-saturation coefficient for heterotrophic biomass;
$K_{S}=S_{S}$ half-saturation coefficient for heterotrophic biomass; $K_{X}=$ half-saturation coefficient for hydrolysis of slowly biodegradable substrate;

$k_{a}=$ ammonification rate;

$k_{h}=$ maximum specific hydrolysis rate;

$Y_{A}=$ yield factor for autotrophic biomass;

$Y_{H}=$ yield factor for heterotrophic biomass;

$\eta_{g}=$ correction factor for $\mu_{H}$ under anoxic conditions;

$\eta_{h}=$ correction factor for hydrolysis under anoxic conditions;

$\mu_{A}=$ maximum specific growth rate for autotrophic biomass; and

$\mu_{H}=$ maximum specific growth rate for heterotrophic biomass.

\section{References}

Belia, E., Amerlinck, Y., Benedetti, L., Sin, G., Johnson, B., and Vanrolleghem, P. A. (2008). "Wastewater systems modelling: Dealing with uncertainties." Proc., Ist IWA/WEF Wastewater Treatment Modelling Seminar, Water Environment Federation, Alexandria, VA.

Benedetti, L., Bixio, D., and Vanrolleghem, P. A. (2006). "Assessment of WWTP design and upgrade options: Balancing costs and risks of standards' exceedance." Water Sci. Technol., 54(6-7), 371-378.

Benedetti, L., de Baets, B, Nopens, I, and Vanrolleghem, P. A. (2010). "Multi-criteria analysis of wastewater treatment plant design and control scenarios under uncertainty." Environ. Model. Softw., 25(5), 616-621.

Brun, R., Kuhni, M., Seigrist, H., Gujer, W., and Reichert, P. (2002). "Practical identifiability of ASM2d parameters-systematic selection and tuning of parameter subsets." Water Res., 36(16), 4113-4127.

Cox, C. D. (2004). "Statistical distribution of uncertainty and variability in activated sludge model parameters." Water Environ. Res., 76(7), 2672-2685.

Dey, A., and Magbanua, B. S., Jr. (2010). "Probabilistic modeling of twostage biological nitrogen removal process: Conditions for enhanced process certitude." Environ. Eng. Sci., 27(12), 1035-1042.

Flores-Alsina, X., Rodríguez-Roda, I., Sin, G., and Gernaey, K. V. (2008). "Multi-criteria evaluation of wastewater treatment plant control strategies under uncertainty." Water Res., 42(17), 4485-4497.

Garman, K. R., Tetreault, M. J., Dold, P. L., Parker, D. S., and Finley, H. R. (1996). "Evaluation of critical activated sludge parameters for dynamic process models." Proc., 69th Annual Water Environment Federation Technical Exposition and Conf., Water Environment Federation, Alexandria, VA.

Gillespie, B., and Carberry, J. J. (1966). "Influence of mixing on isothermal reactor yield and adiabatic reactor conversion." Ind. Eng. Chem. Fundamen., 5(2), 164-171.

GPS-X [Computer software]. (2006). Hydromantis, Hamilton, Canada.

Grady, C. P. L., Jr., Daigger, G. T., and Lim, H. C. (1999). Biological wastewater treatment, 2nd Ed., Marcel Dekker, New York.

Henze, M., Grady, C. P. L., Jr., Gujer, W., Marais, G. V. R., and Matsuo, T. (1987a). "Activated sludge model No. 1." IAWPRC Scientific and Technical Rep. No.1, International Association on Water Pollution Research and Control, London.

Henze, M., Grady, C. P. L., Jr., Gujer, W., Marais, G. V. R., and Matsuo, T. (1987b). "A general model for single-sludge wastewater systems." Water Res., 21(5), 505-515.

Kappeler, J., and Gujer, W. (1992). "Estimation of kinetic parameters of heterotrophic biomass under aerobic conditions and characterization of wastewater for activated sludge modeling." Water Sci. Technol., 25(6), 125-139.

Magbanua, B. S., Jr., and Bowers, A. R. (1998). "Effect of recycle and axial mixing on microbial selection in activated sludge." J. Environ. Eng., 124(10), 970-978.

Martin, C., Eguinoa, I., Mcintyre, N. R., García-Sanz, M., and Ayesa, E. (2007). "ARMA models for uncertainty assessment of time series data: Application to Galindo-Bilbao WWTP." Proc., 7th Int. IWA Symp. on Systems Analysis and Integrated Assessment in Water Management, International Water Association, London. 
Neumann, M. B., von Gunten, U., and Gujer, W. (2007). "Uncertainty in prediction of disinfection performance." Water Res., 41(11), 2371-2378.

Petersen, B., Gernaey, A. K., Henze, M., and Vanrolleghem, P. (2002). "Evaluation of an ASM1 model calibration procedure on a municipal-industrial wastewater treatment plant." J. Hydroinf., 4, 15-38.

Refsgaard, J. C., Van Der Sluijs, J. P., Højberg, A. L., and Vanrolleghem, P. A. (2007). "Uncertainty in the environmental modelling process-a framework and guidance." Environ. Modell. Softw., 22(11), 1543-1556.

Reichert, P., and Vanrolleghem, P. A. (2001). "Identifiability and uncertainty analysis of the River Water Quality Model No. 1 (RWQM1)." Water Sci. Technol., 43(7), 329-338.

Rittman, B. E., and Macarty, P. L. (2001). "Environmental biotechnology." Principles and applications, Mc-Graw Hill, New York.

Rousseau, D., et al. (2001). "Development of a risk assessment based technique for design/retrofitting of WWTPs." Water Sci. Technol., 43(7), 287-294.
Siegrist, H., and Tschui, M. (1992). "Interpretation of experimental data with regard to the activated sludge model No. 1 and calibration of the model for municipal wastewater treatment plants." Water Sci. Technol., 25(6), 167-183.

Sin, G., De Pauw, D. J. W., Weijers, S., and Vanrolleghem, P. A. (2008). "An efficient approach to automate the manual trial and error calibration of activated sludge models." Biotechnol. Bioeng., 100(3), $516-528$.

Sin, G., Gernaey, K. V., Neumann, M. B., van Loosdrecht, M. C. M., and Gujer, W. (2009). "Uncertainty analysis in WWTP model applications: A critical discussion using an example from design." Water Res., 43(11), 2894-2906.

Sin, G., Gernaey, K. V., Neumann, M. B., van Loosdrecht, M. C., and Gujer, W. (2011). "Global sensitivity analysis in wastewater treatment plant model applications: Prioritizing sources of uncertainty." Water Res., 45(2), 639-651.

Tchobanoglous, G., Burton, F. L., and Stensel, H. D. (2002). Wastewater engineering: Treatment and reuse, 4th Ed., Mc-Graw Hill, New York. 